\title{
Sexual function, anxiety and depression in women with benign breast disease. A case-control study
}

\author{
Flávia Fairbanks ${ }^{1}$, Marina Paula Andres ${ }^{1 *}$, Priscila Caldeira $^{1}$, Carmita Abdo $^{2}$, Sergio Podgaec $^{1}$ \\ ${ }^{1}$ Gynecologic Division, Hospital das Clínicas, Faculdade de Medicina, Universidade de São Paulo (HC-FMUSP), São Paulo, SP, Brazil \\ ${ }^{2}$ Department of Psychiatry, HC-FMUSP, São Paulo, SP, Brazil
}

Study conducted at Gynecologic Division, Hospital das Clínicas, Faculdade de Medicina, Universidade de São Paulo (HC-FMUSP), São Paulo, SP, Brazil

Article received: $2 / 28 / 2017$ Accepted for publication: $3 / 1 / 2017$

*Correspondence: Address: Av. Dr. Enéas de Carvalho Aguiar, $255,10^{\circ}$ andar São Paulo, SP - Brazil Postal code: 05403-000 marina.dpandres@gmail.com

\section{SUMMARY}

Introduction: Sexual dysfunction is highly prevalent, affecting $40 \%$ of the female population. The incidence of such dysfunction is known to be higher among women with malignant breast disease and in patients with depression or anxiety. However, there are few data regarding the prevalence of sexual dysfunction among women with benign breast disease (BBD).

Objective: To evaluate the incidence of sexual dysfunction, depression and anxiety among women with BBD, in comparison with that observed for healthy women. Method: We evaluated the incidence of sexual dysfunction in 60 patients with benign breast disease (fibroadenomas, breast cysts, breast pain and phyllodes tumor) and 69 healthy women (control group). Participants completed the Sexual Quotient Questionnaire for Females (SQQ-F), the Beck Depression Inventory and the Beck Anxiety Inventory. Statistical analysis revealed that depression and anxiety were comparable between BBD and control groups (10.3 vs. $20.3 \%$ and 38.7 vs. $34.3 \%$, respectively, p>0.05). The mean SQQ-F score ( $65.6 \pm 22.7$ vs. $70.1 \pm 16.8$; $\mathrm{p}>0.05)$ and sexual dysfunction (33.3 vs. $25.4 \%$; $\mathrm{p}=0.324)$ were similar between $\mathrm{BBD}$ and control groups.

Conclusion: We found no differences between women with BBD and healthy women in terms of the incidence of sexual dysfunction, anxiety and depression. Nevertheless, given the high prevalence of this condition, it is important to assess sexual quality of life, as well as overall quality of life, in women with BBD.

Keywords: depression, anxiety, sexual dysfunction, physiological, sexual behavior, breast diseases.

\section{INTRODUCTION}

Sexual well-being encompasses cognitive, emotional and subjective factors, including individual sexuality, self-esteem, sex life and intimacy in sexual relations. ${ }^{1,2}$ Sexual dysfunction affects 28 to $45 \%$ of all adult women. ${ }^{3,4} \mathrm{~A}$ study of 1,219 women in Brazil showed that $49 \%$ had at least one sexual dysfunction, ${ }^{5}$ including lack of desire, dyspareunia and orgasmic dysfunction.

It is well established that female breast cancer patients suffer from sexual dysfunction, which has been shown to affect approximately $52 \%$ of such patients. ${ }^{4,6}$ That can be attributed to a number of factors. In addition to inducing amenorrhea, ovarian failure and, thus, infertility, chemotherapy, anti-hormone therapy and ovarian suppression can cause alopecia and weight changes, which have a major impact on self-esteem and body image. Adverse drug effects, such as fatigue, bone pain, diarrhea and hypertension, can also decrease interest in, willingness to engage in and desire for sexual activity.

It has been shown that 30 to $40 \%$ of female breast cancer patients experience intense emotional stress that can persist for many years after diagnosis, as well as high levels of anxiety and depression, negatively affecting sexual function. ${ }^{8}$ Medications used to treat emotional stress, such as antidepressants and anxiolytics, modulate the dopaminergic and serotonergic pathways in the central nervous system and increase the levels of prolactin, all of which are involved in sexual response. ${ }^{7-10}$ Breast 
cancer surgery can result in scarring, asymmetry, sensory changes, and a negative self-image. Approximately 33\% of women undergoing mastectomy for breast cancer report that the procedure had a negative impact on their sexual relation with their partners. ${ }^{11,12}$

The impact of breast cancer on sexuality has been extensively studied in recent years and, in many cases, patients with benign breast disease are used as control group, despite the lack of studies investigating sexuality in these women. Benign breast tumors are identified in $80 \%$ of the 1.6 million breast biopsies performed annually in the United States, the most common type being fibroadenoma, which occurs in $10 \%$ of all women over the course of their lives. ${ }^{13}$ Given the lack of data in the literature, the objective of our study was to determine whether women with benign breast disease suffer from sexual dysfunction, anxiety and depression.

\section{Method}

\section{Study population}

Our study involved female patients seen between March 2013 and March 2015 at one of two facilities: the Gynecology Outpatient Clinic of the Department of Obstetrics and Gynecology of University of São Paulo’s School of Medicine and the Vila Regina Primary Care Clinic (operated by the São Paulo Municipal Department of Health, district of Campo Limpo Technical Health Oversight sector). Both facilities are located in the city of São Paulo, Brazil. The study had IRB approval of both institutions, and all participating patients gave written informed consent.
Patients with benign breast disease (BBD group) and without any gynecological disease (control group) were included in the study. The criteria for inclusion in the BBD group were: being $18-45$ years of age; having been diagnosed with benign breast disease, including fibroadenoma, breast cysts, breast pain and phyllodes tumor; and having no history of breast cancer. The inclusion criteria for the control group were being 18-45 years of age and having no gynecological or chronic pain complaints. The participants were recruited among women undergoing routine annual gynecological examinations at a primary care clinic. We, thus, included 60 patients in the BBD group and 69 patients in the control group (Figure 1).

\section{Instruments}

We applied the Sexual Quotient Questionnaire for Females (SQQ-F), translated and adapted into Portuguese by Abdo, to the patients in both groups. ${ }^{14}$ The SQQ-F (Figure 2) consists of ten questions assessing the major domains of female sexual function: desire, arousal, orgasm, comfort and sexual satisfaction. Each question is scored from 0 to 5 , higher scores indicating better function (with the exception of question 7 [regarding pain during intercourse]), where the inverse is true, the score for question 7 being subtracted from, rather than added to the total score. The scores on individual questions are multiplied by two, and the maximum possible total score therefore ranges from 0 to 100. In the interpretation of the total score, sexual performance is categorized as follows: absent to poor ( $0-20$ points); poor to unfavorable

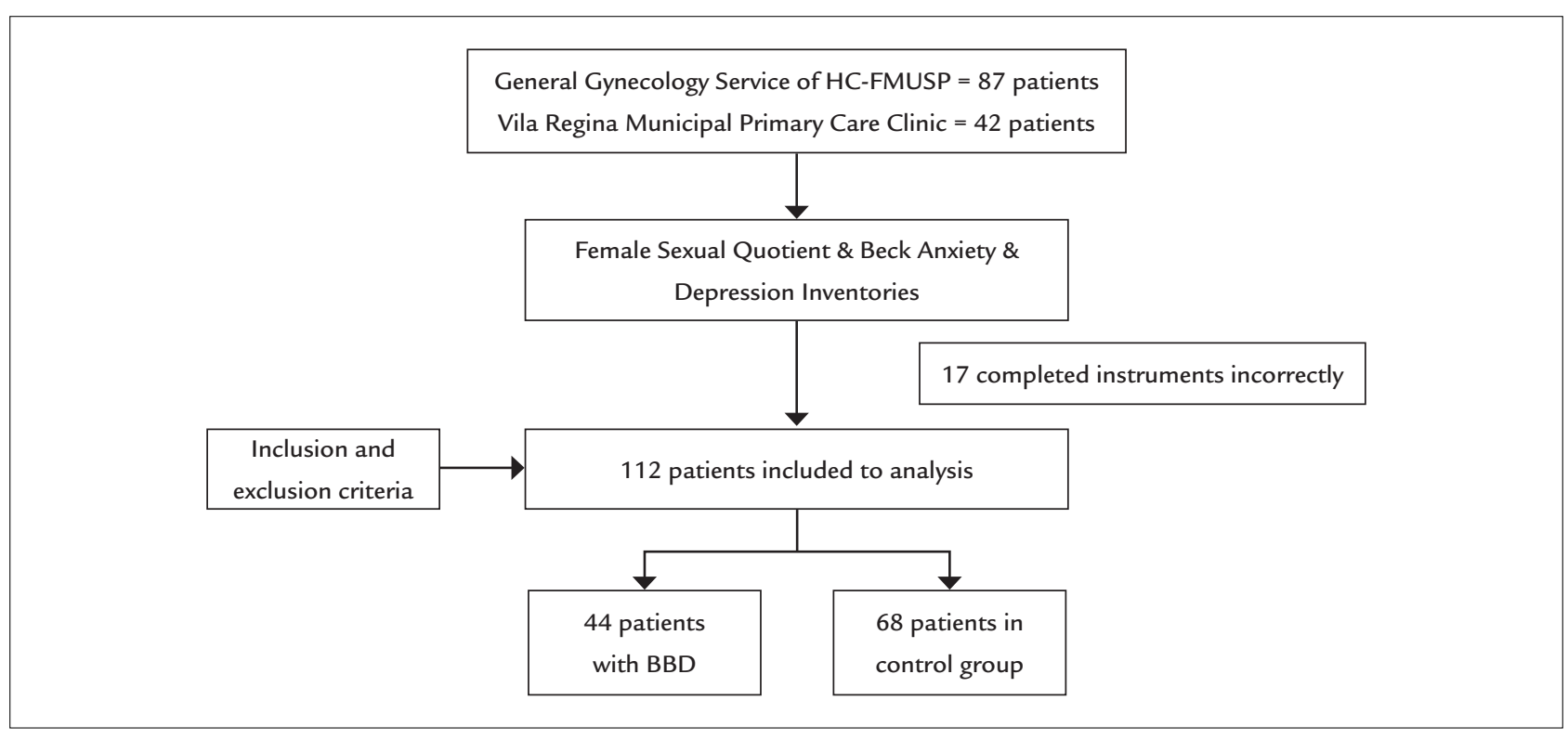

FIGURE 1 Flowchart showing recruitment and women's progress through the study. 


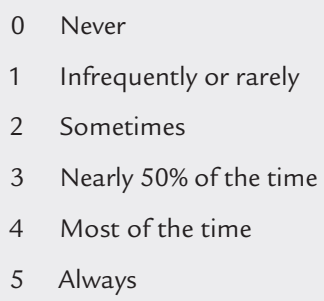

$\begin{array}{llllll}\text { ( ) } 0 & (\text { ( ) } 1 & (\text { ) } 2 & (\text { ) } 3 & \text { ( ) } 4 & \text { ( ) } 5\end{array}$

Question 2. Is your interest in sex sufficient for you to take part in sexual relations enthusiastically?
( ) 0
( ) 1
( ) 2
( ) 3
( ) 4
( ) 5

Question 3. Does foreplay (caressing, kisses, hugs, fondling etc) stimulate you to continue the sexual relation?
( ) 0
( ) 1
( ) 2
( ) 3
( ) 4
( ) 5

Question 4. Do you normally get lubricated (wet) during sexual relations?
( ) 0
( ) 1
( ) 2
( ) 3
( ) 4
( ) 5

Question 5. During sexual relations, as your partner becomes more aroused, do you also feel more stimulated for sex?
( ) 0
( ) 1
( ) 2
( ) 3
( ) 4
( ) 5

Question 6. During sexual relations, do you relax your vagina sufficiently to facilitate the penetration of the penis?
( ) 0
( ) 1
( ) 2
( ) 3
( ) 4
( ) 5

Question 7. Do you normally feel pain during sexual relations when the penis penetrates your vagina?
( ) 0
( ) 1
( ) 2
( ) 3
( ) 4
( ) 5

Question 8. Are you able to get involved without getting distracted (without losing concentration) during sexual relations?
( ) 0
( ) 1
( ) 2
( ) 3
( ) 4
( ) 5

Question 9. Are you able to reach orgasm (maximum pleasure) in the sexual relations you have?
( ) 0
( ) 1
( ) 2
( ) 3
( ) 4
( ) 5

Question 10. Does the level of satisfaction you get from sexual relations make you want to have sex again on other days?
( ) 0
( ) 1
( ) 2
( ) 3
( ) 4
( ) 5

FIGURE 2 Sexual Quotient Questionnaire for Females. ${ }^{14}$

(22-40 points); unfavorable to fair (42-60 points); fair to good (62-80 points); and good to excellent (82-100 points). In addition, the major type of disorder presented by the patient can be diagnosed through the assessment of individual scores by domain (question or group of questions): decreased desire and sexual interest (unfavorable scores on questions 1, 2, and 8); dysfunction in the various phases of arousal (unfavorable scores on questions $3,4,5$, and 6); presence of dyspareunia (an unfavorable score on question 7); and orgasmic dysfunction (unfavorable scores on questions 9 and 10). For question 7 , a score of 4 or 5 was considered unfavorable, whereas a score of 0 or 2 was considered unfavorable for all other questions.

Demographic data, as well as data related to medical history and medication use, were also collected during the interviews. As anxiety and depression are related to sexual dysfunction, we also assessed it using the Portuguese-language version of the Beck Depression Inventory (BDI $)^{15}$ and the Portuguese-language version of the Beck Anxiety Inventory (BAI). ${ }^{16} \mathrm{BAI}$ and BDI are both 21 -item instruments on which each item is scored from 0 to 3 , higher scores indicating greater severity. The severity of anxiety (BAI score) is categorized as follows: minimal (0-7); mild (8-15); moderate (16-25); and severe (26-63). The severity of depression (BDI score) is categorized as follows: minimal (0-9); mild (10-18); moderate (19-29); and severe (30-63).

\section{Statistical analysis}

Qualitative variables are reported as absolute and relative frequencies, and the strength of correlations was tested using Chi-square test, Fisher's exact test or the likelihood ratio test, ${ }^{17}$ the last two being applied when the sample 
was insufficient for use of the Chi-square test. Quantitative variables are reported as means and standard deviations or as medians and ranges, comparisons being made with the Mann-Whitney test. ${ }^{17}$ For all tests, the level of significance was set at $5 \%$.

\section{Results}

We evaluated 69 women in the control group and 60 women in the BBD group. Mean age was comparable between the two groups (31.8 \pm 7.4 and $34.2 \pm 6.7$ years, respectively; range, $18-45$ years). One patient in each group failed to complete the BDI and was therefore excluded from the analysis of depression. In addition, two control group patients and $16 \mathrm{BBD}$ group patients did not satisfactorily complete the BAI and were consequently excluded from the analysis of anxiety.

The mean Beck Depression Inventory score was 9.8 \pm 9.5 and 10.7 \pm 9.4 in control and BBD groups, respectively, whereas the mean Beck Anxiety Inventory score was $13.3 \pm 11.9$ and $15.4 \pm 15.5$. As shown in Table 1 , the overall frequency of moderate to severe depression (as determined on the basis of the BDI scores) was $20.3 \%$ in the BBD group and $10.3 \%$ in the control group, whereas that of moderate to severe anxiety (as determined on the basis of the BAI scores) was 38.7 and $34.3 \%$, respectively, in both groups. There were no significant differences between the groups in terms of depression or anxiety levels.

The control and BBD groups were comparable in terms of the proportion of women who reported having a current sexual partner ( 97.1 and $96.7 \%$, respectively). Table 2 shows that control and BBD groups did not differ significantly in terms of the mean SQQ-F score ( $70.1 \pm 18.6$ vs. $65.6 \pm 22.7$, $\mathrm{p}=0.315$ ) or the resulting diagnosis of sexual dysfunction ( 25.4 vs. $33.3 \%, \mathrm{p}=0.324$ ). In addition, there were no statistical differences between the two groups in the analysis of SQQ-F scores by domain (Table 3).

Sexual desire disorder was the most common dysfunction presented in both groups ( 30.4 vs. $33.3 \%, \mathrm{p}=0.724$ ), followed by orgasm and general sexual satisfaction $(22.1 \%$ vs. $25 \%, \mathrm{p}=0.695$ ) as shown in Table 4.

\section{Discussion}

According to the World Health Organization (WHO), health is an ideal state of physical, mental, emotional, and social well-being, rather than merely the absence of disease. Health is based on four fundamental pillars, one of which is sexual health ${ }^{18}$ which is defined as a state of well being in the physical, emotional, mental, and social aspects of sexual function, rather than simply the absence of sexual dysfunction. The sexual act itself serves not only to strengthen an interpersonal relationship and build selfesteem but also to maintain satisfactory sexual activity. Impairment of any of these aspects can trigger sexual dysfunction, which can ultimately create frustration, worsen quality of life and cause friction in the relationship. ${ }^{19}$

The sexual response cycle is a biological phenomenon that represents natural behavior during sexual stimulation. Various models of the female sexual response have been developed. Currently, the most widely used of such models is the one described in 2001 by Basson, ${ }^{20}$ because it takes into consideration the various domains that influence the physiological sexual response in females. The innovative concept introduced by that model was the proposal that a woman can be in a state of sexual neutrality and, after stimulation, can express desire, thereafter satisfactorily completing the female sexual response cycle.

Rates of sexual dysfunction are known to be higher among individuals with chronic diseases than in the general population. ${ }^{21-24}$ Multiple factors are involved in the pathogenesis of such dysfunction. Decline in the sexual activity of these individuals is primarily attributed to the pain, anxiety and depression that often accompany chronic diseases, as well as to the type of treatment administered. Various studies have shown that addressing the sexuality of patients treated for chronic diseases continues to pose great challenges in routine clinical practice. That is mainly because health care professionals rarely investigate the issue, as well as because the women themselves feel shame and frustration when discussing such problems. ${ }^{22}$

There have been few studies correlating aspects of sexual function with the course of benign gynecological diseases. For example, patients with endometriosis commonly have chronic pelvic pain, which can present together with dysmenorrhea or as dyspareunia per se. In either case, having endometriosis can significantly worsen patient scores in the pain domain of questionnaires that assess sexual function. ${ }^{25,26}$

The female breasts play a dual role: one related to fertility and one related to sexual function. In this context, it is understood that any disease that primarily affects the mammary glands can cause or increase sexual dysfunction. In addition, the subjective risk that a change in the breast, even a characteristically benign change, can prove to be malignant at some point during the treatment often increases the levels of anxiety and depression of women with benign breast disease.

There were no statistically significant differences between control and BBD groups in terms of the scores on anxiety or depression, both of which were comparable to 
those reported for the general population. This suggests that women with benign breast disease, if receiving regular, reliable treatment, show levels of anxiety and depression comparable to those seen in the general population, indicating that benign breast disease has little impact on overall quality of life.
The incidence of anxiety and depression is typically higher among individuals with chronic diseases. ${ }^{27,28}$ In a study drawing comparisons between patients undergoing periodic hemodialysis and renal transplant recipients, Avsar et al. ${ }^{27}$ showed that rates of anxiety and depression were significantly higher in the former group, probably

TABLE 1 Analyses of scores obtained from the Beck Depression Inventory and Beck Anxiety Inventory.

\begin{tabular}{|c|c|c|c|c|c|}
\hline \multirow[t]{2}{*}{ Condition } & \multicolumn{2}{|c|}{ Control } & \multicolumn{2}{|c|}{ BBD } & \multirow[t]{2}{*}{$p$} \\
\hline & $\mathbf{n}$ & $\%$ & $n$ & $\%$ & \\
\hline Depression* & & & & & $0.217^{\dagger}$ \\
\hline Absent & 52 & 76.5 & 42 & 71.2 & \\
\hline Mild & 9 & 13.2 & 5 & 8.5 & \\
\hline Moderate & 4 & 5.9 & 10 & 16.9 & \\
\hline Severe & 3 & 4.4 & 2 & 3.4 & \\
\hline Anxiety f $^{\prime}$ & & & & & $0.972^{\S}$ \\
\hline Absent & 27 & 40.3 & 17 & 38.6 & \\
\hline Mild & 17 & 25.4 & 10 & 22.7 & \\
\hline Moderate & 11 & 16.4 & 8 & 18.2 & \\
\hline Severe & 12 & 17.9 & 9 & 20.5 & \\
\hline
\end{tabular}

BBD: benign breast disease.

${ }^{*}$ Control group $=68$ patients; BDD group $=59$ patients

tLikelihood ratio test.

$\neq$ Control group $=67$ patients; $B D D$ group $=44$ patients.

${ }^{\S}$ Chi-square test.

TABLE 2 Scores obtained from the Sexual Quotient Questionnaire for Females and prevalence of sexual dysfunction.

\begin{tabular}{|c|c|c|c|c|c|c|}
\hline \multirow[t]{2}{*}{ Group } & \multicolumn{2}{|c|}{ SQQ-F score } & \multirow[t]{2}{*}{$\mathbf{p}$} & \multicolumn{2}{|c|}{ Sexual dysfunction } & \multirow[t]{2}{*}{$\mathbf{p}$} \\
\hline & Mean & SD & & $\mathbf{n}$ & $\%$ & \\
\hline Control & 70.1 & 18.6 & $0.315^{*}$ & 17 & 25.4 & $0.324 *$ \\
\hline BBD & 65.6 & 22.7 & & 20 & 33.3 & \\
\hline
\end{tabular}

SQQ-F: Sexual Quotient Questionnaire for Females; SD: standard deviation; BBD: benign breast disease.

${ }^{*}$ Chi-square test.

TABLE 3 Number of patients with sexual disturbance as per individual questions of the Sexual Quotient Questionnaire for Females in both groups (control and benign breast disease - BBD).

\begin{tabular}{|c|c|c|c|c|c|c|}
\hline \multirow{2}{*}{$\begin{array}{l}\text { SQQ-F } \\
\text { question }\end{array}$} & \multirow[t]{2}{*}{ Domain } & \multicolumn{2}{|c|}{ Control } & \multicolumn{2}{|c|}{ BBD } & \multirow[t]{2}{*}{$\mathbf{p}$} \\
\hline & & $\mathbf{n}$ & $\%$ & $\mathbf{n}$ & $\%$ & \\
\hline 1 & Desire/Sexual fantasies & 41 & 59.4 & 35 & 58.3 & 0.900 \\
\hline 2 & Desire/Interest & 27 & 39.7 & 20 & 33.3 & 0.455 \\
\hline 3 & Arousal/Foreplay & 12 & 17.6 & 11 & 18.3 & 0.920 \\
\hline 4 & Arousal/Lubrication & 9 & 13.4 & 14 & 23.7 & 0.135 \\
\hline 5 & Arousal/In tune with partner & 10 & 14.9 & 11 & 18.3 & 0.606 \\
\hline 6 & Penetration/Relaxation & 7 & 10.4 & 12 & 20.7 & 0.112 \\
\hline 7 & Pain/Penetration & 12 & 18.5 & 7 & 11.7 & 0.290 \\
\hline 8 & Desire/Involvement & 26 & 38.8 & 22 & 37.3 & 0.861 \\
\hline 9 & Orgasm & 19 & 27.9 & 22 & 36.7 & 0.291 \\
\hline 10 & General sexual satisfaction & 14 & 20.6 & 17 & 28.3 & 0.307 \\
\hline
\end{tabular}

*Chi-square test.

$\mathrm{N}$ : number of patients with sexual disturbance in each specific domain; SQQ-F: Sexual Quotient Questionnaire for Females; BBD: benign breast disease. 
TABLE 4 Comparison between groups according to results of scores obtained from the Sexual Quotient Questionnaire

for Females.

\begin{tabular}{lllll} 
Disturbance & Group & & Total & P \\
\cline { 2 - 4 } & Control & BBD & & \\
\hline Sexual desire & $21 / 69(30.4)$ & $20 / 60(33.3)$ & $41 / 129(31.8)$ & 0.724 \\
\hline Arousal & $6 / 68(8.8)$ & $5 / 60(8.3)$ & $11 / 128(8.6)$ & 0.921 \\
\hline Pain & $12 / 65(18.5)$ & $7 / 60(11.7)$ & $19 / 125(15.2)$ & 0.290 \\
\hline Orgasm and general satisfaction & $15 / 68(22.1)$ & $15 / 60(25.0)$ & $30 / 128(23.4)$ & 0.695 \\
\hline
\end{tabular}

Chi-square test.

because of the stress caused by the need for long-term monitoring of chronic kidney disease. The authors concluded that resolution of the physical health problem had improved the quality of life and thus the emotional health of the renal transplant recipients. ${ }^{27}$

It should be kept in mind that the abovementioned studies involved patients with chronic diseases that have systemic repercussions and require long-term pharmacological treatment. That is not the case in women with benign breast disease, in whom periodic gynecological follow-up examinations are sufficient. That difference (fewer interventions) might be less disruptive to the everyday life of the patients, thus minimizing the impact that the disease has on their sex life. As previously mentioned, we found no significant differences between the BBD and control groups in terms of sexual function, in any of the domains assessed by the SQQ-F.

Comparison between the two groups demonstrated that sexual desire disturbance was the most common sexual dysfunction found among our patients, a result similar to that of the general population when sexual function is analyzed, and corroborates our hypothesis that benign breast disease does not impair sexual function.

One limitation of our study was the small patient sample size, which comprised 129 women. Therefore, further studies, involving larger samples of women with benign breast disease, are needed in order to corroborate our results. Nevertheless, our study is groundbreaking in that it evaluated, for the first time, sexual function in women with benign breast diseases. Given the high prevalence of this condition, it is important to assess sexual quality of life, as well as overall quality of life, in this population.

\section{Resumo}

Disfunção sexual, ansiedade e depressão em mulheres com câncer de mama benigno. Um estudo de caso-controle

Introdução: A disfunção sexual é altamente prevalente, afetando $40 \%$ da população feminina. A incidência de tal disfunção é conhecida por ser maior entre as mulheres com câncer de mama e pacientes com ansiedade e depressão. No entanto, existem poucos dados sobre a prevalência de disfunção sexual entre mulheres com doença benigna da mama (BBD).

Objetivo: Avaliar a incidência de disfunção sexual, depressão e ansiedade em mulheres com BBD, em comparação a mulheres saudáveis.

Método: Avaliamos a incidência de disfunção sexual em 60 pacientes com doença benigna da mama (fibroadenomas, cistos mamários, dor mamária e tumor phyllodes) e 69 mulheres saudáveis (grupo controle). As participantes completaram o Questionário de Quociente Sexual para Mulheres (SQQ-F), o Inventário de Depressão de Beck e o Inventário de Ansiedade de Beck. A análise estatística revelou que a depressão e a ansiedade eram comparáveis entre os grupos BBD e controle (10,3 vs. $20,3 \%$ e 38,7 vs. $34,3 \%$, respectivamente, $\mathrm{p}>0,05)$. O escore médio de SQQ-F $(65,6 \pm 22,7$ vs. $70,1 \pm 16,8 ; \mathrm{p}>0,05)$ e a disfunção sexual $(33,3$ vs. $25,4 \%$; $\mathrm{p}=0,324$ ) foram semelhantes entre os grupos BBD e controle. Conclusão: Não encontramos diferenças entre mulheres com BBD e mulheres saudáveis em termos de incidência de disfunção sexual, ansiedade e depressão. No entanto, dada a alta prevalência dessa condição, é importante avaliar a qualidade de vida sexual, bem como a qualidade de vida global, em mulheres com BBD.

Palavras-chave: depressão, ansiedade, disfunções sexuais fisiológicas, comportamento sexual, doenças mamárias.

\section{References}

1. Masters WH, Johnson VE. The sexual response cycle of the human female. III. The clitoris: anatomic and clinical consideration. West J Surg Obstet Gynecol. 1962; 70:248-57.

2. Masters WH, Johnson VE. The sexual response of the human male. I. Gross anatomic considerations. West J Surg Obstet Gynecol. 1963; 71:85-95.

3. Hayes RD, Bennett CM, Fairley CK, Dennerstein L. What can prevalence studies tell us about female sexual difficulty and dysfunction? J Sex Med. 2006; 3(4):589-95.

4. Safarinejad MR, Shafiei N, Safarinejad S. Quality of life and sexual functioning in young women with early-stage breast cancer 1 year after lumpectomy. Psychooncology. 2013; 22(6):1242-8. 
5. Nicolosi A, Laumann EO, Glasser DB, Moreira ED Jr, Paik A, Gingell C; Global Study of Sexual Attitudes and Behaviors Investigators' Group. Sexual behavior and sexual dysfunctions after age 40: the global study of sexual attitudes and behaviors. Urology. 2004; 64(5):991-7.

6. Bober SL, Varela VS. Sexuality in adult cancer survivors: challenges and intervention. J Clin Oncol. 2012; 30(30):3712-9.

7. Krebs LU. Sexual health during cancer treatment. Adv Exp Med Biol. 2012; 732:61-76.

8. Dizon DS. Quality of life after breast cancer: survivorship and sexuality. Breast J. 2009; 15(5):500-4.

9. Shifren JL, Monz BU, Russo PA, Segreti A, Johannes CB. Sexual problems and distress in United States women: prevalence and correlates. Obstet Gynecol. 2008; 112(5):970-8.

10. Speer JJ, Hillenberg B, Sugrue DP, Blacker C, Kresge CL, Decker VB, et al. Study of sexual functioning determinants in breast cancer survivors. Breast J. 2005; 11(6):440-7.

11. Kedde H, van de Wiel HB, Weijmar Schultz WC, Wijsen C. Subjective sexual well-being and sexual behavior in young women with breast cancer. Support Care Cancer. 2013; 21(7):1993-2005.

12. Andrzejczak E, Markocka-Mączka K, Lewandowski A. Partner relationships after mastectomy in women not offered breast reconstruction. Psychooncology. 2013; 22(7):1653-7.

13. Lakoma A, Kim ES. Minimally invasive surgical management of benign breast lesions. Gland Surg. 2014; 3(2):142-8.

14. Abdo CHN. Quociente sexual feminino: um questionário brasileiro para avaliar a atividade sexual da mulher. Diagn Tratamento. 2009; 14(2):89-91.

15. Beck AT, Ward CH, Mendelson M, Mock J, Erbaugh J. An inventory for measuring depression. Arch Gen Psychiatry. 1961; 4:561-71.

16. Beck AT, Epstein N, Brown G, Steer RA. An inventory for measuring clinical anxiety: psychometric properties. J Consult Clin Psychol. 1988; 56(6):893-7.

17. Kirkwood BR, Sterne JAC. Essential medical statistics. 2. ed. Oxford: Blackwell Science; 2003. p. 429-46
18. Segre M, Ferraz FC. O conceito de saúde. Rev Saúde Pública. 1997; 31(5):538-42.

19. Clayton A, Ramamurthy S. The impact of physical illnesses on sexual dysfunction. Adv Psychosom Med. 2008; 29:70-88.

20. Basson R. The female sexual response: a different model. J Sex Marital Ther. 2000; 26(1):51-65.

21. Araújo DB, Borba EF, Abdo CHN, Souza LA, Goldestein-Schainberg C, Chahade WH, et al. Função sexual em doenças reumáticas. Acta Reumatol Port. 2010; 35(1):16-23.

22. Lara LAS, Silva ACJRS, Romão APMS, Junqueira FRR. Abordagem das disfunções sexuais femininas. Rev Bras Ginecol Obstet. 2008; 30(6):312-21.

23. Ferreira CC, Mota LM, Oliveira AC, Carvalho JF, Lima RA, Simaan CK, et al. Frequency of sexual dysfunction in women with rheumatic diseases. Rev Bras Reumatol. 2013; 53(1):35-46

24. Abdel-Nasser AM, Ali EI. Determinants of sexual disability and dissatisfaction in female patients with rheumatoid arthritis. Clin Rheumatol. 2006; 25(6):822-30

25. Montanari G, Di Donato N, Benfenati A, Giovanardi G, Zannoni L, Vicenzi $\mathrm{C}$, et al. Women with deep infiltrating endometriosis: sexual satisfaction, desire, orgasm and pelvic problem interference with sex. J Sex Med. 2013; 10(6):1559-66

26. Evangelista A, Dantas T, Zendron C, Soares T, Vaz G, Oliveira MA. Sexual function in patients with deep infiltrating endometriosis. J Sex Med. 2014; 11(1):140-5.

27. Avsar U, Avsar UZ, Cansever Z, Yucel A, Cankaya E, Certez H, et al. Caregiver burden, anxiety, depression, and sleep quality differences in caregivers of hemodialysis patients compared with renal transplant patients. Transplant Proc. 2015; 47(5):1388-91.

28. Mak A, Tang CS, Chan MF, Cheak AA, Ho RC. Damage accrual, cumulative glucocorticoid dose and depression predict anxiety in patients with systemic lupus erythematosus. Clin Rheumatol. 2011; 30(6):795-803. 